\title{
Pengaruh Penambahan Bottom Ash Terhadap Parameter Kuat Geser Tanah Lempung Desa Beureugang Kaway XVI Aceh Barat
}

\author{
Evidasari $^{1{ }^{1 *}}$ Banta Chairullah $\mathbf{M}^{2}$ Halida Yunita $^{3}$ \\ ${ }^{1}$ Mahasiswa, Jurusan Teknik Sipil, Universitas Syiah Kuala, Banda Aceh 23111, Indonesia \\ 2,3 Jurusan Teknik Sipil, Universitas Syiah Kuala, Banda Aceh 23111, Indonesia. \\ Email: evie.dasari97@gmail.com
}

\begin{abstract}
Soil is the foundation of civil construction building that functions to receive and hold the load from structure on it. Soil properties in each region are different and not all of the land are eligible to be used as subgrade construction prior to repair. The treatment that can be done to improve the nature of the land among others by means of chemical stabilization is using a mixture of coal waste (bottom ash). The stabilized soil samples were clay soil from the Beureugang Village, Kaway XVI Subdistrict, Aceh Barat District. The purpose of this study is to determine the effect of bottom ash posed to the properties of plasticity and shear strength. The addition of bottom ash is carried out with a variation of 0\%, 5\%, 10\%, 15\%, and $20 \%$ of the dry weight of the soil. The results showed that the addition of bottom ash on clay Village Beureugang gives an impact on the limits of Atterberg and shear strength value. Lowes PI value addition of $10 \%$ was achieved in the bottom ash which is $20,35 \%$ from the previous $24,90 \%$. The highest value of the friction angle $(\varphi)$ is achieved in mixture of $20 \%$ of bottom ash that is equal to $37.2^{\circ}$, while the value of the lowest friction angle $(\varphi)$ is achieved on the ground without a mixture of bottom ash that is equal to $17.4^{\circ}$. The highest cohesion (c) value is achieved at the $10 \%$ bottom ash mixture that is equal to $0,89 \mathrm{~kg} / \mathrm{cm}^{2}$, while the lowest value of cohesion (c) is achieved in a mixture of bottom ash $20 \%$, i.e $0,53 \mathrm{~kg} / \mathrm{cm}^{2}$. The results showed that the addition of a mixture of bottom ash causes friction angle to increase, however it decreases the cohesion due to the reduced value of bonding strength between the soil particles.
\end{abstract}

Keywords: stabilization, clay, coal waste,bottom ash, shear strength

\begin{abstract}
Abstrak
Tanah merupakan dasar dari suatu konstruksi bangunan sipil yang berfungsi menerima dan menahan beban dari suatu struktur di atasnya. Sifat-sifat tanah di masing-masing daerah berbeda dan tidak semua tanah layak untuk digunakan sebagai tanah dasar konstruksi sebelum dilakukan perbaikan. Tindakan yang dapat dilakukan untuk memperbaiki sifat tanah tersebut antara lain dengan cara stabilisasi kimiawi menggunakan bahan campuran limbah batu bara (bottom ash). Sampel tanah yang distabilisasi merupakan tanah lempung yang berasal dari Desa Beureugang, Kecamatan Kaway XVI, Kabupaten Aceh Barat. Tujuan dari penelitian ini untuk mengetahui pengaruh yang ditimbulkan bottom ash terhadap sifat plastisitas dan kuat geser tanah. Penambahan bottom ash dilakukan dengan variasi $0 \%, 5 \%, 10 \%, 15 \%$, dan $20 \%$ dari berat kering tanah. Hasil penelitian menunjukkan bahwa penambahan bottom ash pada tanah lempung Desa Beureugang berpengaruh pada batas-batas Atterberg dan nilai kuat geser tanah. Nilai indeks plastisitas (PI) terendah dicapai pada penambahan 10\% bottom ash yaitu $20,35 \%$ dari yang sebelumnya $24,90 \%$. Untuk Nilai sudut geser $(\phi)$ tertinggi dicapai pada campuran $20 \%$ bottom ash yaitu sebesar $37,2^{\circ}$, sedangkan nilai sudut geser $(\phi)$ terendah dicapai pada tanah tanpa campuran bottom ash yaitu sebesar $17,4^{\circ}$. Nilai kohesi (c) tertinggi dicapai pada campuran bottom ash $10 \%$ yaitu sebesar $0,89 \mathrm{~kg} / \mathrm{cm}^{2}$, sedangkan nilai kohesi (c) terendah dicapai pada campuran bottom ash $20 \%$ yaitu $0,53 \mathrm{~kg} / \mathrm{cm}^{2}$. Hasil penelitian menunjukkan bahwa penambahan campuran bottom ash secara umum menyebabkan sudut geser meningkat, namun menyebabkan nilai kohesi turun dikarenakan berkurangnya daya lekat antar partikel tanah.
\end{abstract}

Kata kunci : stabilisasi, tanah lempung, limbah batu bara, bottom ash, kuat geser 


\section{PENDAhULUAN}

Tanah merupakan dasar dari suatu konstruksi bangunan sipil yang berfungsi menerima dan menahan beban dari suatu struktur di atasnya. Sifat tanah di masing-masing daerah berbeda dan tidak semua tanah layak untuk dapat digunakan sebagai tempat ditumpunya konstruksi, salah satu contohnya tanah lempung yang berasal dari Desa Beureugang, Kecamatan Kaway XVI, Kabupaten Aceh Barat. Secara teori tanah lempung tidak baik digunakan untuk konstruksi sipil, karena tanah lempung memiliki kekuatan geser yang rendah dan indeks plastisitas yang tinggi. Hal ini menjadikan lempung sebagai material yang kurang baik untuk suatu pekerjaan konstruksi, baik untuk tempat berdirinya suatu konstruksi maupun sebagai bahan timbunan konstruksi.

Fungsi tanah sebagai tempat berdirinya bangunan memerlukan kondisi tanah yang stabil sehingga apabila ada kondisi tanah yang buruk maka diperlukan adanya perbaikan yang lebih dikenal dengan istilah soil stabilization. Stabilisasi tanah adalah suatu tindakan yang dilakukan guna memperbaiki sifat-sifat fisis dan mekanis tanah. Stabilisasi tanah dapat dilakukan dengan dua cara, yakni stabilisasi mekanis yang dilakukan dengan cara memadatkan tanah dengan menggunakan peralatan mekanis, dan stabilisasi kimiawi dengan menggunakan bahan pencampur yang dilakukan dengan cara mencampurkan tanah dengan bahan stabilisasi seperti semen, kapur, limbah batu bara (fly ash dan bottom ash), serbuk marmer, atau bahan lainnya yang bersifat menimbulkan reaksi kimiawi.

Kuat geser tanah merupakan salah satu sifat mekanis tanah yang erat hubungannya dengan kestabilan dan kemampuan geser tanah dalam mempertahankan struktur butirnya dari keruntuhan yang diakibatkan oleh gaya luar. Kuat geser tanah terdiri dari nilai sudut geser $(\phi)$ dan nilai kohesi (c). Di lapangan, kuat geser tanah sangat dipengaruhi oleh berbagai faktor seperti keadaan tanah, jenis tanah, dan kadar air. Sementara di laboratorium kuat geser tanah dipengaruhi oleh metode percobaan, kualitas sampel, tingkat regangan dan kadar air.

Pada penelitian ini dilakukan stabilisasi kimiawi dengan menggunakan bottom ash sebagai bahan campuran. Bottom ash yang digunakan merupakan hasil produksi dari PT. Mifa Bersaudara yang berada di Desa Peunaga Cut Ujong, Kecamatan Meurebo, Kabupaten Aceh Barat. Bottom ash sama halnya dengan fly ash merupakan hasil sisa pembakaran batu bara pada pembangkit listrik. Abu batu bara pada dasarnya tidak memiliki sifat mengikat, namun dengan adanya air dan kandungan silikaoksida ( $\mathrm{SiO} 2$ ) yang ada di dalam abu batu bara akan bereaksi secara kimia untuk menghasilkan zat yang memiliki kemampuan mengikat, Polii [1].

Variasi penambahan bottom ash yang dilakukan adalah $0 \%, 5 \%, 10 \%, 15 \%$, dan $20 \%$ dari berat kering tanah. Pengujian yang dilakukan adalah pengujian sifat-sifat fisis tanah seperti berat jenis, batas cair, batas plastis, pembagian butir, dan pengujian mekanis tanah seperti uji pemadatan (standard proctor) dan pengujian kuat geser langsung (direct shear).

Penelitian ini bertujuan untuk mengetahui pengaruh penambahan bottom ash terhadap sifat plastisitas dan parameter kuat geser tanah.

\section{TINJAUAN PUSTAKA}

\section{A. Klasifikasi Tanah}

Menurut Subekti [2] tanah atau soil dapat diklasifikasikan dengan berbagai cara sesuai dengan penggunaannya dalam berbagai disiplin ilmu. Terdapat dua sistem klasifikasi yang sering digunakan dalam ilmu geoteknik yaitu USCS (Unified Soil Classification System) dan AASHTO (American Association of State Highway and Transportation Official). Kedua sistem tersebut menggunakan sifat-sifat indeks tanah sederhana seperti distribusi ukuran butiran, batas cair, batas plastis, dan indeks plastisitas, Hardiyatmo [3].

\section{B. Botttom Ash}

Bottom ash adalah material hasil sisa pembakaran batu bara yang tidak sempurna yang memiliki partikel menyerupai pasir dengan karakteristik fisik berwarna abu-abu gelap, berbentuk butiran berporos sehingga dianggap mampu mengurangi penggunaan pasir, Lubis dan Karolina [4].

Batu bara yang diproduksi PT. Mifa Bersaudara berjenis subbituminous. Subbituminous adalah jenis batu bara dengan kualitas sedang di antara jenis lignite dan bituminous. Secara fisik subbituminous memiliki ciri-ciri berwarna coklat gelap cenderung hitam, memiliki kelembaban yang lebih rendah dari jenis lignite, dan cocok digunakan untuk bahan bakar pembangkit listrik tenaga uap. Unsur-unsur kimiawi yang terkandung di dalam bottom ash dapat dilihat pada Tabel 1 berikut ini. 
Tabel 1. Unsur Kimia Dalam Bottom Ash

\begin{tabular}{|c|c|c|c|}
\hline No & Parameter & Satuan & Hasil \\
\hline 1 & $\mathrm{SiO}_{2}$ & $\%$ & 42.87 \\
2 & $\mathrm{Al}_{2} \mathrm{O}_{3}$ & $\%$ & 16.94 \\
3 & $\mathrm{Fe}_{2} \mathrm{O}_{3}$ & $\%$ & 7.43 \\
4 & $\mathrm{CaO}$ & $\%$ & 15.75 \\
5 & $\mathrm{MgO}$ & $\%$ & 9.12 \\
6 & $\mathrm{TiO}_{2}$ & $\%$ & 0.73 \\
7 & $\mathrm{Na}_{2} \mathrm{O}$ & $\%$ & 0.47 \\
8 & $\mathrm{~K}_{2} \mathrm{O}$ & $\%$ & 0.90 \\
9 & $\mathrm{Mn}_{3} \mathrm{O}_{4}$ & $\%$ & 0.461 \\
10 & $\mathrm{P}_{2} \mathrm{O}_{5}$ & $\%$ & 0.395 \\
11 & $\mathrm{SO}_{3}$ & $\%$ & 4.39 \\
\hline
\end{tabular}

Sumber : PT. Mifa Bersaudara (2019)

\section{Pengujian Kuat Geser Dengan Uji Direct Shear}

Menurut Hardiyatmo [3] kuat geser adalah gaya perlawanan yang dilakukan oleh butir-butir tanah terhadap gesekan atau tarikan.

$$
\tau=\mathrm{c}+\sigma \operatorname{tg} \phi
$$

di mana:

$\tau=$ kuat geser tanah $\left(\mathrm{kN} / \mathrm{m}^{2}\right)$;

$\mathrm{c}=$ kohesi tanah $\left(\mathrm{kN} / \mathrm{m}^{2}\right)$;

$\phi=$ sudut geser dalam tanah $\left(^{\circ}\right)$; dan

$\sigma=$ tegangan normal pada bidang runtuh $\left(\mathrm{kN} / \mathrm{m}^{2}\right)$.

\section{Penelitian Terdahulu}

Beberapa penelitian mengenai pengaruh penambahan bottom ash yang berhubungan dengan penelitian ini berdasarkan penelitian terdahulu dapat dilihat pada uraian berikut ini :

1. Indera dkk (2016) telah meneliti pengaruh penambahan fly ash dengan variasi $0 \%, 10 \%$, 20\%, dan 30\% dengan judul Stabilisasi Tanah dengan Menggunakan Fly Ash dan Pengaruhnya Terhadap Nilai Kuat Tekan Bebas. Hasil penelitiannya menunjukan penambahan fly ash dapat menurukan nilai liquid limit (LL) dan nilai berat jenis tanah dengan kadar fly ash $20 \%$ dan waktu pemeraman selama 21 hari.

2. Polii dkk (2018) dengan judul Pengaruh Penambahan Abu Batu Bara Terhadap Kuat Geser Tanah Lempung, dengan variasi campuran $0 \%, 5 \%, 10 \%, 15 \%, 20 \%$, dan $25 \%$. Dari hasil penelitian yang dilakukan, pada pengujian pemadatan terjadi peningkatan pada campuran $25 \%$ abu batu bara. Untuk nilai kohesi terbesar yaitu $6.35 \mathrm{t} / \mathrm{m} 2$ dari $2.52 \mathrm{t} / \mathrm{m} 2$ pada campuran $20 \%$ abu batu bara. Untuk nilai sudut geser dalam dari $(\phi)=12^{\circ}$ menjadi $(\phi)=17^{\circ}$ pada campuran $15 \%$ dan $25 \%$ abu batu bara dan tegangan geser terbesar pada campuran $25 \%$.

\section{METODE PENELITIAN}
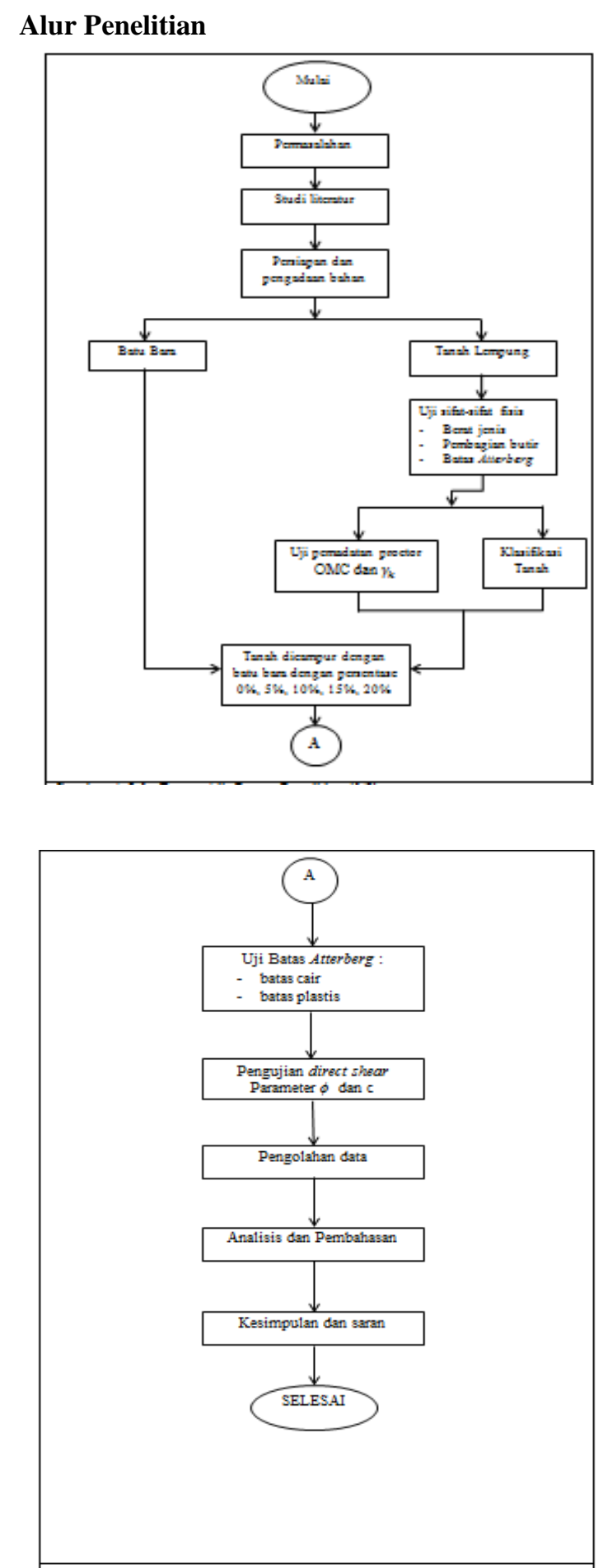

Gambar 1Bagan Alur Penelitian 


\section{A. Objek Penelitian}

Objek pada penelitian ini adalah tanah lempung yang diambil dari Desa Beureugang, Kecamatan Kaway XVI, Kabupaten Aceh Barat. Tanah ini distabilisasi menggunakan bottom ash dengan variasi campuran $0 \%, 5 \%, 10 \%, 15 \%$ dan $20 \%$.

\section{B. Jenis dan Sumber Data}

Sumber data yang digunakan dalam penelitian ini meliputi data primer dan data sekunder. Data primer adalah data utama yang diperlukan dalam analisis hasil penelitian dan data sekunder adalah data pendukungnya.

\section{Data primer}

Data ini diperoleh dari hasil pemeriksaan atau pengujian langsung di laboratorium, terdiri dari data sifat-sifat fisis tanah seperti berat jenis, batas plastis, batas cair, dan pembagian butir, dan data sifat-sifat mekanis tanah yaitu pemadatan tanah dan parameter kuat geser tanah yaitu sudut geser $(\phi)$ dan kohesi (c).

\section{Data sekunder}

Data sekunder merupakan data pendukung yang diperlukan dalam penelitian di antaranya angka koreksi benda uji pada saat perhitungan, angka kalibrasi alat uji, serta peta lokasi pengambilan tanah dan lain sebagainya. Data sekunder diperoleh dari instansi-instansi terkait, studi literatur dan konsultasi.

\section{HASIL DAN PEMBAHASAN}

Hasil penelitian dan pengolahan data yang disajikan meliputi pengujian sifat-sifat fisis berupa berat jenis, batas cair, batas plastis, pembagian butir, klasifikasi tanah berdasarkan AASHTO dan USCS. Pengujian sifat mekanis yaitu pemadatan (Standard Proctor) dan pengujian kuat geser tanah dengan alat direct shear.

\section{A. Hasil Pengujian Sifat-sifat Fisis Tanah}

Berdasarkan penelitian yang telah dilakukan terhadap tanah lempung Desa Beureugang, Kecamatan Kaway XVI, Kabupaten Aceh Barat, diperoleh hasil pengujian sifat-sifat fisis tanah lempung yang terdiri dari berat isi, berat jenis, batas-batas Atterberg dan analisa saringan. Hasil pengujian sifat-sifat fisis tanah diperlihatkan dalam Tabel 2. berikut ini.
Tabel 2. Hasil Pengujian Sifat-sifat Fisis Tanah

\begin{tabular}{|c|l|l|}
\hline No & \multicolumn{1}{|c|}{ Parameter Pengujian } & \multicolumn{1}{|c|}{$\begin{array}{c}\text { Hasil } \\
\text { Pengujian }\end{array}$} \\
\hline 1 & Berat Jenis & 2,339 \\
\hline 2 & Batas-batas Atterberg & \\
\hline & a. Batas Cair (LL) & $62,99 \%$ \\
\hline & b. Batas Plastis (PL) & $38,09 \%$ \\
\hline 3 & c. Indeks Plastisitas (PI) & $24,90 \%$ \\
\hline 4 & Analisa Saringan (lolos \#200) & $92,484 \%$ \\
\hline & Pengelompokan Tanah & \\
\hline & a. AASHTO (Group Index) & A-7-5 (24) \\
\hline & b. USCS & CH \\
\hline
\end{tabular}

\section{B. Pemadatan}

Tujuan dari pengujian pemadatan yaitu untuk memperoleh berat volume kering maksimum ( $\gamma \mathrm{k}$ maks) dan kadar air optimum (OMC). Kadar air optimum dan berat volume kering $(\gamma \mathrm{k})$ yang dihasilkan pada penelitian ini digunakan untuk menggambarkan grafik hubungan antara kadar air dan berat volume kering seperti yang diperlihatkan pada Gambar 1.

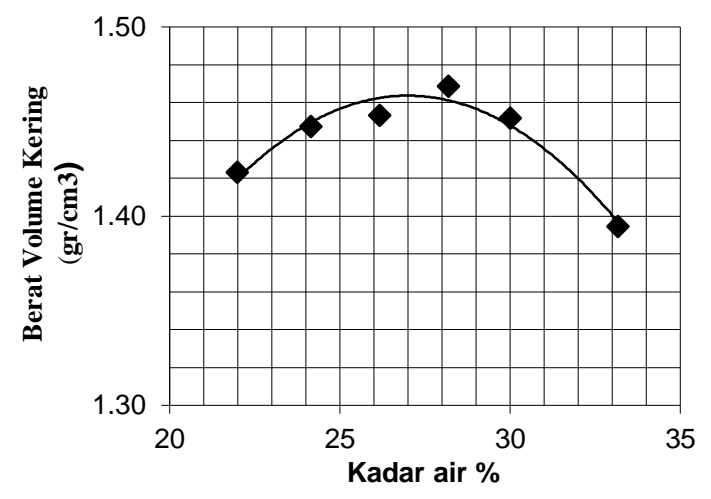

Gambar 2 Grafik Hubungan Kadar Air dan Berat Volume Kering

Tabel 3. Hasil Pengujian Pemadatan

\begin{tabular}{|c|c|c|}
\hline Pemadatan & $\begin{array}{c}\text { Berat Isi Kering } \\
\text { Maksimum }\left(\mathrm{gr} / \mathrm{cm}^{3}\right)\end{array}$ & $\begin{array}{c}\text { Kadar Air } \\
\text { Optimum } \\
(\%)\end{array}$ \\
\hline Tanah asli & 1,466 & 27,08 \\
\hline
\end{tabular}

\section{Hasil Pengujian Batas-batas Atterberg Tanah Campuran Bottom Ash}

Hasil pengujian batas-batas Atterberg yang meliputi batas cair (LL), batas plastis (PL), dan indeks plastisitas (PI) dengan variasi persentase campuran bottom ash $0 \%, 5 \%, 10 \%, 15 \%$ dan 20\% dapat dilihat dalam Tabel 4. 
Tabel 4. Hasil Pengujian Batas-batas Atterberg Tanah dengan Variasi Campuran Bottom Ash

\begin{tabular}{c|c|c|c}
\hline \multirow{2}{*}{$\begin{array}{c}\text { Variasi Persen } \\
\text { Campuran } \\
\text { Bottom Ash }\end{array}$} & \multicolumn{3}{|c}{ Batas-batas Atterberg $(\%)$} \\
\cline { 2 - 4 } & $\begin{array}{c}\text { Batas Cair LL } \\
(\%)\end{array}$ & Batas Plastis PL (\%) & $\begin{array}{c}\text { Indeks Plastisitas PI } \\
(\%)\end{array}$ \\
\hline 0 & 62,99 & 38,09 & 24,90 \\
\hline 5 & 60,49 & 38,23 & 22,25 \\
\hline 10 & 61,39 & 41,04 & 20,35 \\
\hline 15 & 63,30 & 40,01 & 23,28 \\
\hline 20 & 64,73 & 38,47 & 26,26 \\
\hline
\end{tabular}

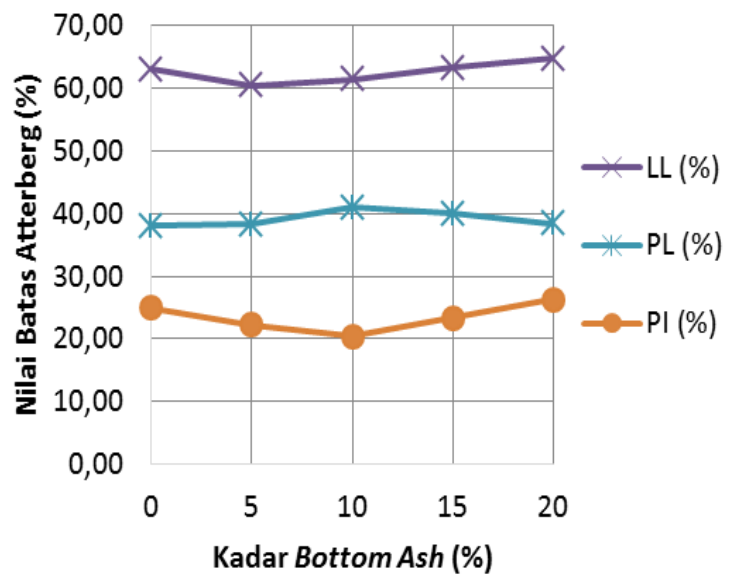

Gambar 3 Grafik Hubungan Kadar Bottom Ash dengan Batas Atterberg

Tabel 4 dan Gambar 2 memperlihatkan bahwa penambahan bottom ash pada tanah sangat jelas mempengaruhi batas-batas Atterberg. Pada campuran $5 \%$ bottom ash nilai batas cair menurun dari $62,99 \%$ menjadi $60,49 \%$, akan tetapi pada campuran $10 \%$, $15 \%$, dan $20 \%$ nilai batas cair kembali meningkat menjadi masing-masing $61,39 \%, 63,30 \%$, dan 64,73\%. Pada campuran 5\% dan $10 \%$ bottom ash nilai batas plastis meningkat dari sebelumnya $38,09 \%$ menjadi $38,23 \%$ dan $41,04 \%$, namun selanjutnya batas plastis kembali mengalami penurunan pada campuran $15 \%$ dan $20 \%$ yaitu $40,01 \%$ dan $38,47 \%$. Nilai indeks plastisitas tanah cenderung menurun pada campuran $5 \%$ dan $10 \%$ dari $24,90 \%$ menjadi $22,25 \%$ dan $20,35 \%$, dengan penurunan terbesar terjadi pada campuran $10 \%$ yaitu $20,35 \%$. Pada campuran $15 \%$ dan $20 \%$ nilai indeks plastisitas kembali mengalami peningkatan menjadi $23,28 \%$ dan $26,26 \%$.

\section{Hasil Pengujian Direct Shear}

\begin{tabular}{|c|c|c|}
\hline $\begin{array}{c}\text { Variasi } \\
\text { Persen } \\
\text { Campura } \\
\mathbf{n} \text { Bottom } \\
\text { Ash }\end{array}$ & \multicolumn{2}{|c|}{ Parameter Kuat Geser } \\
\cline { 2 - 3 } & Sudut Geser $\left(^{\circ}\right)$ & Kohesi $\mathbf{( k g / \mathbf { c m } ^ { 2 } )}$ \\
\hline $0 \%$ & 17,4 & 0,86 \\
\hline $5 \%$ & 21,3 & 0,86 \\
\hline $10 \%$ & 22,9 & 0,89 \\
\hline $15 \%$ & 33,0 & 0,77 \\
\hline $20 \%$ & 37,2 & 0,53 \\
\hline
\end{tabular}

Dari Tabel 5 di atas dapat dilihat adanya peningkatan sudut geser dan penurunan nilai kohesi (c) pada benda uji dengan kandungan bottom ash yang semakin besar. Peningkatan maksimum nilai sudut geser $(\phi)$ terjadi pada kondisi pencampuran $20 \%$ bottom ash yaitu sebesar $37,2^{\circ}$. Peningkatan maksimum nilai kohesi (c) terjadi pada kondisi pecampuran $10 \%$ bottom ash sebesar $0,89 \mathrm{~kg} / \mathrm{cm} 2$.

\section{Pengaruh campuran bottom ash terhadap sudut geser}

Penambahan bottom ash dengan variasi 0\%, 5\%, 10\%, 15\%, 20\% pada tanah lempung Desa Beureugang memberikan pengaruh pada besarnya nilai sudut geser $(\phi)$ dan kohesi (c). Untuk melihat pengaruh campuran bottom ash terbaik untuk sudut geser ditampilkan garis yang memperlihatkan pola kecenderungan pengaruh yaitu dengan melihat pola linear yang terjadi. Hasil tersebut dapat dilihat pada Gambar 3.

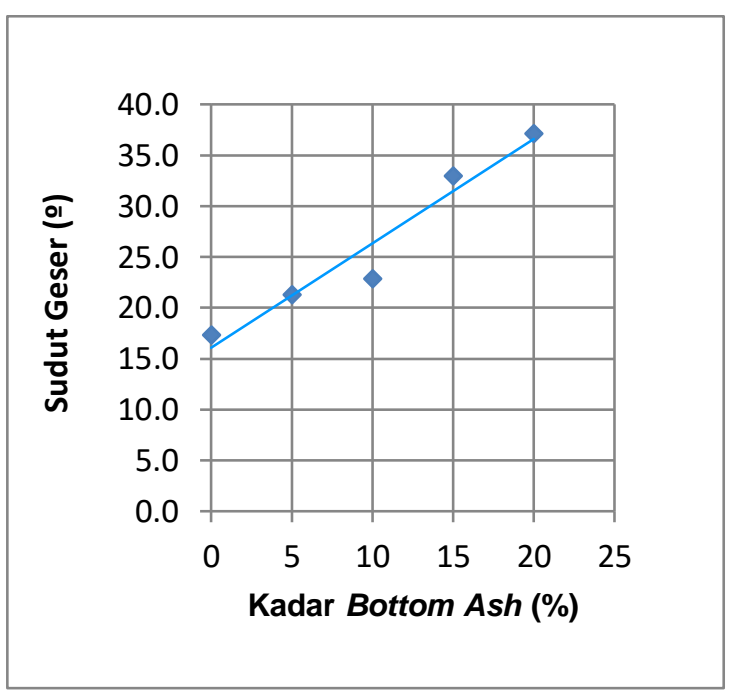

Gambar 4 Grafik Hubungan Penambahan Bottom ash dengan Sudut Geser

Pada Gambar 3 memperlihatkan secara umum pengaruh penambahan bottom ash yang sangat signifikan meningkatkan nilai sudut geser 
$(\phi)$ dengan persentase campuran bottom ash yang semakin besar sampai $20 \%$. Peningkatan nilai sudut geser $(\phi)$ diperkirakan karena terjadinya peningkatan bidang kontak antar butiran akibat penambahan bottom ash.

\section{Pengaruh campuran bottom ash terhadap nilai kohesi}

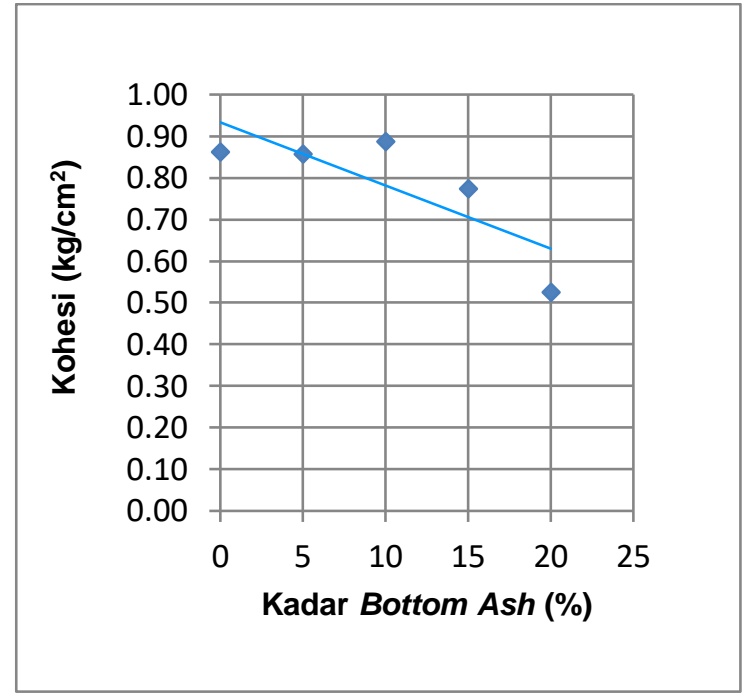

Gambar 5 Grafik Hubungan Penambahan Bottom Ash dengan kohesi

Gambar 4 menunjukkan bahwa penambahan bottom ash hingga persentase $10 \%$ dengan menyebabkan peningkatan nilai kohesi dari $0,86 \mathrm{~kg} / \mathrm{cm}^{2}$ menjadi $0,89 \mathrm{~kg} / \mathrm{cm}^{2}$, selanjutnya pada persentase campuran $15 \%$ dan $20 \%$ bottom ash nilai kohesi (c) kembali turun menjadi $0,77 \mathrm{~kg} / \mathrm{cm}^{2}$ dan $0,53 \mathrm{~kg} / \mathrm{cm}^{2}$. Peningkatan nilai kohesi (c) disebabkan adanya perubahan reaksi antara partikel tanah dengan butiran bottom ash.

\section{KESIMPULAN DAN SARAN}

\section{A. Kesimpulan}

Hasil penelitian dan pembahasan yang telah diuraikan sebelumnya dapat diambil beberapa kesimpulan sebagai berikut ini.

1. Tanah dari Desa Beureugang termasuk ke dalam golongan A-7-5 (15) menurut sistem klasifikasi AASHTO dan termasuk ke dalam lempung anorganik plastisitas tinggi yang disimbolkan dengan $\mathrm{CH}$ menurut sistem USCS.

2. Kekuatan geser tanah asli pada kondisi kepadatan proctor diperoleh nilai sudut geser $(\phi)$ sebesar $17,4^{\circ}$ dan nilai kohesi (c) sebesar $0,85 \mathrm{~kg} / \mathrm{cm}^{2}$.
3. Penambahan campuran bottom ash $10 \%$ dapat menurunkan nilai indeks plastisitas tanah dari $24,90 \%$ menjadi 20,35\%. Penurunan ini merupakan penurunan terbesar dibandingkan dengan campuran $5 \%, 15 \%$, dan $20 \%$.

4. Penambahan bottom ash dapat meningkatkan nilai sudut geser $(\phi)$ hingga kadar $20 \%$ bottom $a s h$. Nilai sudut geser $(\phi)$ tertinggi yang dicapai pada penambahan $20 \%$ bottom ash yaitu sebesar $37,2^{\circ}$, sedangkan nilai sudut geser $(\phi)$ terendah yang dicapai pada tanah tanpa campuran bottom ash yaitu sebesar $17,4^{\circ}$.

5. Penambahan bottom ash juga dapat meningkatan nilai kohesi (c) sampai persentase campuran $10 \%$ bottom ash dengan masa tunggu 3 hari yaitu dari $0,86 \mathrm{~kg} / \mathrm{cm}^{2}$ menjadi $0,89 \mathrm{~kg} / \mathrm{cm}^{2}$.

6. Penambahan bottom ash yang memberikan pengaruh paling optimum pada tanah lempung Desa Beureugang adalah pada persentase campuran $20 \%$ untuk nilai sudut geser $(\phi)$ dan pengaruh paling optimum untuk nilai indeks plastisitas (PI) tanah dicapai pada persentase campuran $10 \%$.

\section{B. Saran}

1. Penelitian ini dapat dilanjutkan dengan menambahkan campuran material lain selain bottom ash seperti kapur, semen, serbuk marmer, dan bahan stabilisasi lainnya.

2. Penelitian ini dapat dilanjutkan dengan kadar bottom ash yaitu 21\% - 30\% dan menambah waktu pemeraman dari 3 hari dan 7 hari untuk mengetahui seberapa jauh pengaruhnya pada persentase campuran bottom ash yang besar.

3. Untuk penelitian selanjutnya disarankan untuk mencari nilai kadar air optimum tiap volume campuran bottom ash dan tanah yang akan digunakan sebagai bahan campuran bottom ash dan tanah.

\section{DAFTAR PUSTAKA}

1. Polii, S. N. Sompie, O. B. A. Dan Manaroinsong, L. D. K. Pengaruh Penambahan Abu Batu Bara Terhadap Kuat Geser Tanah Lempung, Jurnal Tekno 16(69):11-15, 2018.

2. Subekti, I. Geologi Teknik, Teknosain, Yogyakarta, 2017.

3. Hardiyatmo, H. C. Mekanika Tanah I, Penerbit Universitas Gadjah Mada, Yogyakarta, 2002.

4. B. M. Das, Mekanika Tanah (Prinsip-prinsip Rekayasa Geoteknis), Penerbit Erlangga, Jakarta, 1995 
5. I. Subekti, Geologi Teknik, Teknosain, Yogyakarta, 2017.

6. Lubis, N. dan Karolina, R. Optimasi Subtitusi Fly Ash dan Bottom Ash Terhadap Pembuatan
Paving Block Sesuai SNI 03-0691-1996, Jurnal

Teknik Sipil USU 6(1), 2017. 